\title{
Performance Task As Instrument For Evaluation Among Grade VI Pupils In Public Elementary Schools
}

\author{
Michel C. Omela ${ }^{1}$, Matronillo M. Martin ${ }^{2 *}$ \\ ${ }^{1}$ Faculty, Planas Elementary School, Ramon, Isabela, Philippines \\ ${ }^{2}$ College of Education, Ifugao State University Potia Campus, Philippines \\ *Corresponding author: matt_martin122680@yahoo.com
}

Received: 01 April 2020; Accepted: 25 April 2020; Published: 28 April 2020

To cite this article (APA): Martin, M. D. M., \& Omela, M. C. (2020). Performance task as instrument for evaluation among grade vi pupils in public elementary schools. Asian Journal of Assessment in Teaching and Learning, 10(1), 41-50. https://doi.org/10.37134/ajatel.vol10.1.5.2020

To link to this article: https://doi.org/10.37134/ajatel.vol10.1.5.2020

\begin{abstract}
This study aimed at determining the status of implementation and usefulness of Performance Task Evaluation (PTE) as an evaluation tool among Grade-VI pupils of Ramon District for the School Year 2018-2019. In this study, the implementation and usefulness of PTE were analyzed using quantitative research. In addition, related factors in implementing the evaluation model were determined. Then, based on the findings, programs and interventions were developed to improve the academic achievement of the Grade VI pupils through PTE. The respondents believed that PTE is being implemented in terms of practices. Therefore, the implementation of the PTE should be considered as a tool of evaluation. The respondents believed that PTE is useful in terms of academics, attitude and instructions. Pupils believed that PTE is useful in providing learning skills necessary for the education since PTE develops the skills of every pupil. Besides, through PTE pupil enhances their skills and potential using the updated and reliable assessment and evaluation tool. The faculty and pupils should attend seminars that will gain knowledge for the implementation of PTE to easily develop a solution or action for its effective implementation. Besides, improved the monitoring system of the implementation of PTE through seminars, trainings, workshop and additional assessment examination. Moreover, the Department of Education Ramon District and recognized pupil government organizations may provide co-curricular activities that would allow maximum participation of the pupils to experience different challenges in education towards a better appreciation of their currently enrolled in elementary through PTE.
\end{abstract}

Keywords: Performance, Evaluation, Task-Oriented, Instrument, Tool

\section{INTRODUCTION}

Education aims to provide learnings and knowledge, also to enhance the skills and abilities of every student, to bring competence, and guide them with positive attitude and values. Quality education considered as an important factor to produce competent professionals in order to build a strong nation and to bring out the best way to get along with global competition. Education is facing challenges in terms of worldwide movement of international students mostly from the Asian and African continents to universities in the West to provide an important source of income to those receiving universities (Biggs \& Tang, 2010). In trying to strengthen the quality assurance system in Philippine education, basic education learning was mandated to upgrade education curricular offerings to performance task and standards (Valdez, 2012).

Spady (1994) stated that outcomes-based education is designed so that all students are equipped with the knowledge, skills and qualities needed to be successful after they exit the educational system. In this system, pupils can excel with their own interest and acquired knowledge in different ways in no particular time. In PTE, what the learners should learn must be identified first, followed by how they are going to learn these. The assessment and teaching strategies will be dependent on the desired learning outcomes unlike in the traditional planning, the lessons that should be learned will be identified first and 
from these lessons the outcomes will be identified (Acharya, 2003).

Performance assessments have become a major tool for educational reform and have captured the attention of policymakers, practitioners, researchers, and stakeholders such as principals, teachers, students, and parents. Performance assessments are defined as concrete and authentic tasks that require students to do something with their knowledge and skills, such as give a demonstration or presentation, or write a report (Nitko, 2014; Shavelson, 2014). They focus on doing something, not merely knowing, and on process as well as product (Linn \& Gronlund, 2013).

Many educators and researchers have recognized the limitations of standardized multiple-choice tests (Frederiksen, 2012; Shepard, 2013). Many problems with multiple choice tests are related to two key assumptions of the tests - decomposability and decontextualization (Resnick \& Resnick, 2012). The decomposability implies that the tests measure independent pieces of knowledge. The decontextualization implies that the tests measure a competency in a context very different from the context in which it is practiced or used. The main task of multiple-choice tests is to select or guess one right answer rather than to construct or create an answer.

Advances in cognitive psychology theory forced educators to acknowledge how complex learning is and how diverse are the means needed to assess learning fully and fairly (Resnick, 2012). According to early theories of learning based on behaviorism, complex higher-order skills are acquired bit-by-bit by breaking learning down into a series of prerequisite skills, called a building-blocks-of-knowledge approach. It was assumed that after basic skills had been learned by rote memorization, they could be assembled into complex understandings. However, research on contemporary cognitive thinking reveals that mental processes related to thinking are not restricted to a higher-order stage of mental development. Instead, higher-order thinking, such as reasoning, is intimately involved in learning even basic levels of reading, mathematics, and other school subjects. In other words, the three R's (reading, writing, and arithmetic) involve important components of inference, judgment, and active mental construction. For example, research on memorizing shows that even in "Learning the Facts," mental elaboration and judgment are required for success (Brown, 2015). Students cannot effectively memorize the facts without organizing knowledge.

Shepard (2000) summarized the new findings from constructivist learning theories. First, intellectual abilities are socially and culturally developed. Cognitive abilities are developed as parents or other significant adults interpret and guide children in their interactions. Second, learners construct knowledge and understanding within a social context. Third, new learning is shaped by prior knowledge and cultural perspectives. Students with more prior knowledge can reason more profoundly, elaborate as they study, and therefore learn more effectively in that knowledge domain. Fourth, learning involves "metacognition" or self-monitoring of learning and thinking. Expert learners are able to control their own learning using a variety of self-monitoring strategies. Fifth, deep understanding supports transfer. Finally, cognitive performance depends on dispositions and personal identity. In other words, affective skills and motivation are as important as knowledge in learning.

Most reform efforts in education take one of two strategies. One is to change teachers' beliefs about education and to extend their knowledge about pedagogy and content. Because this strategy is costly in personnel and time, most reform efforts take the second strategy, which is known as "measurementdriven instruction" (Popham, 2015). Measurement-driven instruction (MDI), as first introduced by Popham, refers to the use of testing as a "catalyst to improve instruction." According to Popham, "measurement-driven instruction occurs when a high-stakes test of educational achievement, because of the important contingencies associated with the students' performance, influences the instructional program that prepares students for the test." In other words, in high-stakes environments, where the results of tests determine rewards, sanctions, or public scrutiny and loss of professional status, the tests will influence what teachers teach and what students learn.

The use of performance assessments is not a new type of test format in education. Essays, oral presentations, and projects have been used in elite private education. Also, in many classrooms in public schools, performance assessments have been used in the form of assigned papers, reports, and projects. A performance assessment requires a student to execute a task or process and bring it to completion (Wiggins, 2013). In other words, a student performs, creates, or produces something over a long period of time to permit evaluation of either the process or the product, or both. The emphasis of performance assessments is on doing, while multiple-choice tests focus on knowing (Linn \& Gronlund, 2013). Many performance assessments imitate actual workplace activities or real-life skill applications that require higher-order thinking skills. Performance assessments can be individual or group oriented. Also, there is 
no single method of "performance assessment." Rather, there are many different measurement approaches including assessment of both processes and products (Taylor \& Nolen, 2004). The processes are assessed by live performances (e.g., speeches, instrumental solos, the process of scientific investigations, and debates, etc.) during direct observation of students as they engage in the performance itself. Performance products (e.g., essay tests, written reports, poems, three-dimensional mathematical models, computer Web sites, and paintings, etc.) are assessed by concrete products of students' works. According to Baron (2012), performance assessment is defined as a constructed response in which students are actively engaged in solving a realistic problem that demands more than simply recalling memorized knowledge. The problem may be relatively limited (requiring five minutes or more), or it may be "enriched," extending over many days and encompassing a broad, sustained, loosely structured project dealing with the central ideas in a discipline.

Linn and Baker (2016) identified a number of characteristics of performance assessments. They are as follows: (a) the use of open-ended tasks; (b) tasks that focus on higher-order or complex skills; (c) tasks that employ context-sensitive strategies; (d) tasks that use complex problems requiring several types of performance and significant student time; (e) tasks that may require group, as well as individual, performance; and (f) tasks that allow for a significant degree of student choice. As is evident from this list of characteristics of performance assessments, the types of knowledge and skills required of the student are different from those that are required of the student in multiple-choice tests. Also, the ultimate intent of performance assessments, which is for the student to construct an answer to the problem, is different from that of multiple-choice tests, which is for the student to simply select or guess one right answer.

Performance Based Assessments are here for the foreseeable future. If past experience is any lesson, individual PBAs will almost certainly prove less reliable than traditional assessment approaches. However, supporters would argue that this compromise in reliability means an upgrade in terms of greater construct validity for skills not easily assessed using traditional approaches. Furthermore, "next generation" assessment approaches that distribute assessment opportunities throughout the school-year (e.g., through-course assessments) may help to partially offset low reliability of a single PBA by taking a composite over multiple assessment tasks and occasions (Wise, 2015).

Moreover, there are ways of making PBAs, even those used for classroom purposes, more reliable and comparable. For example, thoughtful reflection on the construct to be assessed (Messick, 2014), coupled with carefully-crafted test specifications (Haertel \& Linn, 2016, can go a long way in creating comparable tasks. Although the measurement field has traditionally avoided classroom assessment, certain groups have begun participating in collaborative initiatives to create curricula with psychometricallysound, embedded PBAs (Furtak et al., 2008).

Doing this well requires new assessment development models that incorporate close collaboration between curriculum designers and assessment developers to ensure tight alignment and seamless integration of assessment and instruction. Such models also require closer collaboration between the content specialists who write the tasks and the psychometricians charged with collecting evidence to support overall assessment quality.

Performance assessment is assessment based on observation and judgment. The assessor observes a student perform a task or reviews a student produced product, and then evaluates the quality of that task or product. While performance tasks can be designed to have students demonstrate their understanding through the application of acquired knowledge to a new and different situation, good performance tasks always involve more than one acceptable solution, often calling for students to explain or defend their solutions. Performance tasks are both an integral part of learning and an opportunity for assessing student performance quality (Arter \& McTighe, 2012).

In spite of these drawbacks, the public continues to give standardized test scores great weight. When these scores have serious consequences such as state financing, student placement, or town ranking, teachers find they must "teach to the test," a practice resulting in the corruption of instruction. Teaching to the test cheapens and undermines the authenticity of the scores as being accurate measures of what students know. It also creates an unbalanced emphasis on tested areas, at the expense of untested areas. For example, teachers often find they must discard essay-type tests since those kinds of tests are inefficient for multiple-choice test preparation. The most efficient type of instruction for the multiple-choice format is instruction that consists of drill and practice on isolated, decontextualized skills (Popham, 2014).

Definitely, this study would serve as an eye opener of the school heads and teachers on how to evaluate the performance of the pupils. This would also a reference paper to be utilized on the extent of 
giving appropriate assessment or evaluation tool in the different learning areas. Performance Task Evaluation contributes to the small but growing empirical literature on evaluation and assessment practices by extending the research to the entire country or even in East Asia. Likewise, this research study provides an initial analysis and formative evaluation of the implementation and usefulness of Performance Task Evaluation to improve evaluation practices in the grassroots level particularly in Ramon District, Division of Isabela using aggregated classroom-level formative evaluation and performance task evaluation.

Generally, the study aimed to determine the status of implementation and usefulness of PTE as an evaluation tool among Grade VI pupils of Ramon District for the School Year 2018-2019. Specifically, this study sought to answer the following questions: (1) What is the status of implementation of PTE as perceived by the Grade VI teachers in terms of practices and environment? (2) What is the level of usefulness of PTE in terms of academics; attitudes; and instruction? (3) What is the significant relationship between the extent of implementation and the level of usefulness of PTE among Grade VI pupils?

\section{METHODOLOGY}

Descriptive design was utilized in this study to arrive at the answers to the research problems. Descriptive study attempts to determine the extent of a relationship between two or more variables using statistical data. In this type of design, relationships between and among a number of facts are sought and interpreted. This type of research would recognize trends and patterns in data. In this study, the implementation and usefulness of PTE was analyzed using quantitative research. Quantitative research attempts to determine the extent of a relationship between two or more variables using statistical data. In addition, related factors in implementing the evaluation model were determined. Then, based on the findings, programs and interventions were developed to improve performance and academic achievement of the Grade VI pupils. The study was conducted to all public elementary schools of DepEd Ramon District. There are 21 complete elementary schools which composed kindergarten to Grade VI levels. Forty-two (42) public school teachers teaching Grade VI classes of Ramon District served as the sample of this study. Respondents were selected using total enumeration. The researchers asked permission from the office of the Schools District Supervisor to conduct the study. Upon approval, the researchers were asked permission from the school heads to allow their teachers as respondents of the study. Then, the teachers were informed about the study.

For the data gathering, the researchers administered the survey questionnaire. Then, the data were summarized, tallied, computed the result as basis for analysis and discussion. The researchers used questionnaire adopted from (Borsoto, 2014) which focused on the outcomes-based evaluation so, simple modification was made in order to fit the objective of the study. The researchers consulted proper authorities in the preparation of the questionnaire, which has two parts.

The first part consisted of nine (9) indicators about the status of implementation of PTE as perceived by the Grade VI pupils in terms of practice and environment respectively. The second part consisted of fourteen (14) indicators about the level of usefulness of PTE in terms of academics, attitudes and instruction respectively. The questionnaire was validated by the supervisor through content validation and underwent through test - retest analysis and obtained reliability score of 0.78 using the Cronbach alpha signifies that the instrument is reliable. The data were gathered, classified, tallied, and tabulated and subjected to the following statistical tools. Descriptive and inferential statistics were calculated and summarized. The weighted mean was computed to identify the level of implementation and usefulness of PTE among the Grade VI pupils. The Pearson $r$ was used to test the significant relationship between the implementation and usefulness of Performance Task Evaluation.

For the purpose of data analysis and qualitative interpretation, Likert-typed scale was used with corresponding values from 1 to 4 scales, one being the lowest and four being the highest. The computed mean ratings were evaluated according to the following interval scale as follows: $3.26-4.00$ : Very Useful (VU)/ Highly Implemented (HI); 2.51 - 3.25: Useful (U)/ Implemented(I); 1.76 - 2.50: Less Useful (LU)/Less Implemented (LI); and 1.00 - 1.75: Not Useful (NU)/Not Implemented (NI). 


\section{RESULTS AND DISCUSSION}

\section{Status of implementation of PTE}

\section{Practices}

Table 1 shows that there was high implementation of the PTE as perceived by the Grade VI pupils in terms of practices mean of 3.48. It was further strengthened with high implementation among the indicators of the two categories. This connotes that the PTE was highly observed and considered as a relevant tool by the teachers. The findings supported the study of Tomas (2015) that practice in terms of performance tasks evaluation helps the students more knowledgeable about the subject matter.

Moreover, indicator 1, "PTE ensures that the learners know exactly what is expected from them as unit standards make it very clear what is required form them" and indicator 4, "PTE provides a chance for the students to undergo remedial or other corrective actions for learning" obtained the highest mean of 3.58 while indicator 5, "PTE requires the students to keep their exams and activities in a portfolio for analysis" obtained the mean of 3.46. Additionally, other indicators were relatively the same means of 3.38. This implicates that in terms of practices of PTE were highly implemented among the teachers. The findings ensure that through PTE, the learners are expected to master the learning competencies.

Table 1. Status of implementation of PTE in terms of practices

\begin{tabular}{|l|c|c|}
\hline \multicolumn{1}{|c|}{ Indicators } & Mean & QE \\
\hline $\begin{array}{l}\text { 1. PTE ensures that the learners know exactly what is expected from them as unit standards } \\
\text { make it very clear what is required form them }\end{array}$ & 3.58 & HI \\
\hline $\begin{array}{l}\text { 2. PTE provides well-defined assessment criteria that are clear to both assessors and learners on } \\
\text { how assessment will take place. }\end{array}$ & 3.38 & HI \\
\hline 3. PTE ensures a more objective assessment and fair result of the predetermined criteria. & 3.38 & HI \\
\hline $\begin{array}{l}\text { 4. PTE provides a chance for the students to undergo remedial or other corrective actions for } \\
\text { learning. }\end{array}$ & 3.58 & HI \\
\hline 5. PTE requires the students to keep their exams and activities in a portfolio for analysis. & 3.46 & HI \\
\hline \multicolumn{1}{|c|}{ Overall Mean } & 3.48 & HI \\
\hline
\end{tabular}

Legend: HI - Highly Implemented

\section{Environment}

Table 2 presents that there was high implementation of the PTE as perceived by the Grade VI pupils in terms of environment mean of 3.47. It was further reinforced with high implementation with regard to the environment. The findings in the implementation of PTE in terms of practices supported the study of Valdez (2012) that the curriculum should be designed to prepare the graduates and demonstrate the core competencies expected of them in the workplace and in the environment.

Likewise, indicator 4, "PTE promotes values formation and character traits ideal to different employment settings" obtained the highest mean of 3.50 while indicator 3 , "PTE provides learning environment that caters the development of pupils as future high school students" obtained the lowest mean which means "highly implemented." Furthermore, all role- players due to the extensive level of consultation and stakeholder involvement and fosters a better integration between education at school and community were also highly implemented among the teachers which obtained the means of 3.46 and 3.48 respectively.

This means that graduates are the ultimate products of education. They move in every part of the high school education to showcase their skills and competencies and be involved in the development of every nation and their environment (Dotong, 2014). 
Table 2. Status of implementation of PTE in terms of environment

\begin{tabular}{|l|c|c|}
\hline \multicolumn{1}{|c|}{ Indicators } & Mean & QE \\
\hline $\begin{array}{l}\text { 1. There is greater support for PTE from all role- players due to the extensive level of } \\
\text { consultation and stakeholder involvement }\end{array}$ & 3.46 & HI \\
\hline 2. PTE fosters a better integration between education at school and community. & 3.48 & HI \\
\hline $\begin{array}{l}\text { 3. PTE provides learning environment that caters the development of pupils as future high } \\
\text { school students. }\end{array}$ & 3.42 & HI \\
\hline 4. PTE promotes values formation and character traits ideal to different employment settings. & 3.50 & $\mathrm{HI}$ \\
\hline \multicolumn{1}{|c|}{ Mean } & 3.47 & $\mathrm{HI}$ \\
\hline
\end{tabular}

Legend: HI - Highly Implemented

\section{The level of usefulness of PTE}

\section{Academics}

As gleaned on Table 3, the pupils believed that the PTE is very much useful specifically in improving the students' academic performance. Moreover, each indicator in terms of academics were also evaluated very useful. This shows that the pupils recognize the relevance of the PTE in their learning process.

Additionally, PTE and its increasing numbers of dedicated educators have become convinced that traditional studies are simply not rich enough to portray the changes that PTE as an evaluation tool may inspire pupils in terms of academic aspect. (Newmann and Archbald, 2012). This study supported the findings that in terms of academic through PTE pupils were helped to measure their own performance.

Table 3. Level of usefulness of PTE in terms of academics

\begin{tabular}{|l|c|c|}
\hline \multicolumn{1}{|c|}{ Indicators } & Mean & QE \\
\hline 1. Helping the pupils measure their own performance & 3.75 & VU \\
\hline $\begin{array}{l}\text { 2. Promoting the responsiveness of the school activities towards the enhancement of } \\
\text { pupils' academic performance }\end{array}$ & 3.54 & VU \\
\hline 3. Developing the study habits of the pupils & 3.56 & VU \\
\hline 4. Strengthening the capabilities and skills of the pupils & 3.60 & VU \\
\hline \multicolumn{1}{|c|}{ Overall Mean } & 3.61 & VU \\
\hline
\end{tabular}

Legend: VU - Very Useful

Table 3 further shows that in terms of promotion of responsiveness of the school activities towards the enhancement of pupils' academic performance, develop study habits among pupils and strengthen the capabilities and skills of pupils were rated very useful in terms of academic aspect of the implementation of PTE. Accordingly, Block et al. (2014) include PTE in their conceptual overview of mastery learning, but mastery learning is not the only way to implement PTE. The fact that people who practice authentic evaluation also claim to engage in PTE suggests the breadth of the concept and mastery of the subject matter. This may support the result of the study that PTE is very useful in terms of developing the study habits of the pupils. Grade VI pupils are still in the period of adjustment in the transition of K to 12 curriculum, faculty members must be considerate enough in giving them adequate and reasonable time to prepare for examination and submit their assignments and projects (Laguador, 2013).

\section{Attitudes}

As presented on Table 4, the respondents professed that in terms of attitudes in utilizing PTE is very useful. Additionally, all indicators from 1 to 5 were rated very useful which obtained 3.56, 3.58,3.56,3.67 and 3.67 mean respectively with 3.61 overall mean correspondingly. This shows that the pupils distinguish the importance of the PTE in their learning process in terms of attitudes. 
Table 4. Level of usefulness of PTE in terms of attitudes

\begin{tabular}{|l|c|c|}
\hline \multicolumn{1}{|c|}{ Indicators } & Mean & QE \\
\hline 1. Challenging the pupils to become more competitive & 3.56 & VU \\
\hline 2. Practicing collaboration rather than competition & 3.58 & VU \\
\hline 3. Creating a mindset towards a clear direction of learning & 3.56 & $\mathrm{VU}$ \\
\hline 4. Motivating the pupils to be independent & 3.67 & $\mathrm{VU}$ \\
\hline $\begin{array}{l}\text { 5. Helping learners to accept responsibility for learning, as they are now at the center } \\
\text { of the learning process. }\end{array}$ & 3.67 & $\mathrm{VU}$ \\
\hline \multicolumn{1}{|c|}{ Overall Mean } & 3.61 & $\mathrm{VU}$ \\
\hline
\end{tabular}

Legend: VU - Very Useful

The overall mean of 3.61 signifies that the PTE is useful in developing the attitude of the Grade VI pupils. The development of well-rounded personality with a healthy outlook and orientation towards intelligent, ethical, and active participation in professional as well as community welfare activities and the development of critical thinking skills that will enable them to participate in research activities and respond to challenges of the profession (Valdez et al, 2012). Pupils sometimes get bored and they feel like irritated until they finally submit their papers with incomplete solutions without discussion of results (Laguador, 2013).

Likewise, the results implicate that challenging the pupils to become more competitive, practice collaborative effort, creating a mindset towards a clear direction of learning, motivating the pupils to be independent and helping learners to accept responsibility for learning were rated very useful. This means that attitudes in the implementation of the PTE should be considered. Indeed, the implementation of PTE among pupils related to attitudinal aspects is very useful.

\section{Instruction}

Table 5 shows the level of usefulness of PTE in terms of Instruction. PTE is considered useful in improving learning skills necessary for the education and in making the teachers more of a facilitator than a lecturer. It is also considered useful in simplifying the execution of the lessons and requiring faculty members to master their subjects being handled. In creating a conducive atmosphere for teaching and learning process, PTE is also considered useful by the respondents.

The overall mean score of 3.63 implies that the PTE is very useful in delivering appropriate instruction. Pupils believe that PTE is useful in providing learning skills necessary for the education since PTE develops the skills of every student and enhances using the new learning system.

Table 5. Level of usefulness of PTE in terms of instruction

\begin{tabular}{|l|c|c|}
\hline \multicolumn{1}{|c|}{ Indicators } & Mean & QE \\
\hline 1. Requiring faculty members to master their subjects being handled. & 3.63 & VU \\
\hline 2. Simplifying the execution of the lessons. & 3.60 & VU \\
\hline 3. Asking the teachers more of a facilitator than a lecturer. & 3.67 & VU \\
\hline 4. Creating a conducive atmosphere for teaching and learning process. & 3.65 & VU \\
\hline 5. Providing learning skills necessary for real like situation & 3.62 & VU \\
\hline \multicolumn{1}{|c|}{ Overall Mean } & 3.63 & VU \\
\hline
\end{tabular}

Legend: VU-Very Useful

Moreover, each indicator of the level of usefulness of PTE in terms of instruction were also evaluated very useful. This shows that the pupils recognize the relevance of the PTE in their learning process. The results supported the study of Laguador (2013) that commitment to accomplish a certain task within the specified period of time must be strongly acquired by the students in submitting their school assignments, activities and projects. Besides, asking the teachers more of a facilitator than a lecturer was rated very useful. Indeed, under the implementation of the PTE, the teacher serves as facilitator rather than a lecturer. 


\section{Significant relationship between the extent of implementation and the level of usefulness of PTE}

Table 6 reveals that there is a significant positive correlation between the implementation of the PTE among the pupils and its relevance to them ranging from 0.28 to 0.51 . However, only the implementation in terms of practices is moderately related with its usefulness in the academic, $r=0.51$, while the rest have either low or negligible relationship. This implies that the PTE when fully implemented can improve the academic performance of the pupil. The usefulness of PTE in terms of academics, attitude and instruction is directly related to its implementation in terms of practices and environment. This shows that the higher the implementation of PTE, the higher the results or being useful of PTE in terms of academics, attitude and implementation.

Table 6. Significant relationship between the extent of implementation and the level of usefulness of PTE

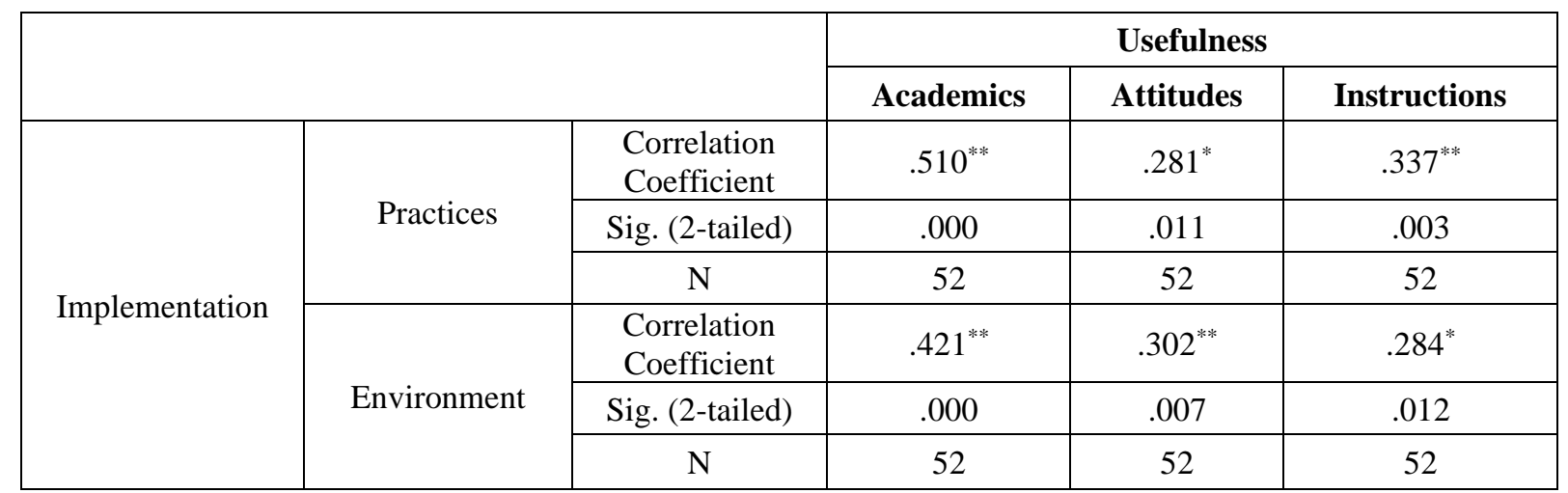

**. Correlation is significant at the 0.01 level (2-tailed).

*. Correlation is significant at the 0.05 level (2-tailed).

\section{CONCLUSION AND RECOMMENDATION}

Based on the findings of the research study, the following conclusions were drawn: the respondents believed that PTE is being implemented in terms of practices. Therefore, the implementation of the PTE considered as a tool of evaluation; considering the implementation of PTE in terms of environment, the is reinforced with high implementation with regard to the environment. Hence, the PTE with regard to environment has its good impact on the pupils' evaluation tool; the respondents believed that PTE is useful in terms of academics, attitude and instructions. Hence, this type of evaluation tool serves as one way to improve the evaluation tool among the grade schoolers. Besides, PTE has its significant effects in the performance of the pupils; through PTE pupils distinguish the importance of the PTE in their learning process in terms of attitudes. Hence, in the evaluation among the pupils, the attitudes must be given considerations; pupils believe that PTE is useful in providing learning skills necessary for the education since PTE develops the skills of every pupil. Besides, through PTE pupil enhances their skills and potential using the updated and reliable assessment and evaluation tool; PTE is useful in improving pupils' potential and skills necessary for the education. Indeed, in the implementation of PTE teachers are more of a facilitator than a lecturer; and the usefulness of PTE in terms of academics, attitude and instruction is directly related to its implementation in terms of practices and environment. Therefore, the higher the implementation of PTE as a tool the it very in terms of academics, attitude and implementation.

In the light of the findings and conclusions drawn from the results of the study, the Department of Education should continue strengthening the implementation of PTE in different schools through the following recommendations: (1) The district shall have a continuous and sustainable monitoring of the implementation of PTE as a tool through the use of data base system to be introduced among the teachers; (2) Improve the monitoring system of the implementation of PTE through seminars and additional assessment examination. Moreover, the school heads should provide intensive training about the authentic form of evaluation tool to be utilized among the pupils; (3) The school heads shall conduct activities intended for pupils about the importance of PTE. Besides, the school heads shall organize school committee about the evaluation and assessment tool who religiously monitor the implementation of it; (4) 
The teachers should craft other authentic evaluation tool based on the standard of PTE. Aside from that, the researcher recommends that evaluation tool must be properly monitored by the evaluation committee of the school; (5) The Department of Education must always be updated with the current trends and needs of the basic education. The curriculum should be designed to prepare the graduates and demonstrate the core competencies expected of them perform well in their high school education; and (6); The DepEd Ramon District and recognized pupil government organization may provide co-curricular activities that would allow maximum participation of the pupils to experience different challenges in education towards a better appreciation of their currently enrolled in elementary through PTE. Knowing the pupils better through interviews will give surface analysis of problems that will open to a deeper sense and cause of the academic dilemma inside the classroom.

\section{REFERENCES}

Acharya, M. K. (2003). A comparative study on washback of English-speaking tests in high schools: Based on twoway and one-way speaking tests. Unpublished Master's Thesis, Ewha Woman's University, Korea.

Arter G.F. and McTigche, M. B. (2012). The effect of performance assessment method on the learning of overhand toss in volleyball. Unpublished Master's Thesis, Keimyung University,Korea.

Baron, N. W. (2012). The effect of portfolio-based instruction on composition students' final examination scores, course grades, and attitudes toward writing. Research in the Teaching of English, 27(2), 155-174.

Block, J. H., H. E. Efthim, and R. B. Burns. (2014). Building Effective Mastery Learning Schools. New York: Longman.

Brown D. K. (2015). Classroom assessment, student motivation, and achievement in high school social studies classes. Applied Measurement in Education, 16(1), 27-54.

Borsoto, K. L. (2014). The effect of portfolio assessment on the and the Performance task Evaluation in Basic Education. Unpublished Master's Thesis, National University of Education, Korea.

Dotong, K. B. (2014). Validity analysis of a state writing assessment. Paper presented at the annual meeting of the National Council on Measurement in Education, Chicago, IL.

Fredriksen, K. Y. (2012). Effect of performance assessment on achievement and creative thinking. Unpublished Master's Thesis, Kongju National University of Education, Korea. 155

Furtak, P. K. et.al. (2008). An investigation of personal investment levels among non-music major piano students using portfolio assessment. Unpublished Doctoral Dissertation, University of North Texas.

Laguador, J L. 2013). The use of and attitudes toward performance assessment in a primary grade program of whole language. Unpublished Doctoral Dissertation, Ohio State University.

Laguador, J.M. (2013d). Observed Classroom Behaviour as Predictor of the Major Examination Results in Advanced Statistics of BS Industrial Engineering Students, International Journal of Management, IT and Engineering, 3(7): 349-360.

Linn, B. I. and Baker, F.D. (2016). The study for the improvement of a mathematics teaching learning method: Focusing on performance assessment about a function part of a middle school. Unpublished Master's Thesis, Kook Min University, Korea.

Linn G.J and Gronlound H.R. (2013). The effect of elementary science classes using portfolio on students' academic achievement and perceptions. Unpublished Master's Thesis, Seoul National University of Education, Korea.

Newmann, F. M., and D. A. Archbald. (2012).The Nature of Authentic Academic Achievement." In Toward a New Science of Educational Testing and Assessment, edited by H. Berlak, F. M. Newmann, E. Adams, D. A. Archbald, T. Burgess, J. Raven, and R. A. Romberg. Albany: State University of New York Press.

Nitko, H.D. (2014). Using CBM to explore a consequential basis for the validity of a state-wide performance assessment. Diagnostique, 22(3), 447-463.

Popham, S. W. (2015). Designing and measuring educational outcomes utilizing student portfolios for business management education, Journal of Instructional Psychology, 28(1), 50-58.

Popham, S. W. (2014) Measuring educational outcomes utilizing student portfolios for business management education, Journal of Instructional Psychology, 41(1), 16-25.

Resnik, C. S. (2013). The effect of the study on the extension of the ability by the adapted learning of the descriptive assessment in performance assessment methods: Focused on the common mathematics in high school. Unpublished Master's Thesis, Kong Ju University, Korea.

Shepard, L. A., Flexer, R. J., Hiebert, E. H., Marion, S. F., Mayfield, V., \& Weston, T. J. (2000). Effects of introducing classroom performance assessments on student learning. Educational Measurement: Issues and practices, 7-18. 
Spady, J. K. (1994). The Issues in Outcomes-Based Education and Instruction in University. Journal on Multidisciplinary in Education.

Taylor, S. and Nolen P.D. (2004). Performance trends and use of accommodations on a statewide assessment: Students with disabilities in the KIRIS on-demand assessments from 1992-1993 through 1995-1996. State Assessment Series, Maryland/Kentucky Report 3, National Center on Educational Outcomes, Minneapolis, MN. 170

Tomas, H. K. (2015). Improving listing skills and motivation. Unpublished Master's Thesis, Ateneo De Manila

Valdez, A.P., Panganiban, C.A., Lumanglas, K.R.L., Calingasan, K.A., Divino, R.S., Guico, P.J.P., Montalbo, G.S., Pronobe, J.M. (2012). The Six-Month Intership Training Program for Medical Laboratory Science Education: An Initial Evaluation, JPAIR: Multidisciplinary Journal, 9(1), 269-283.

Valdez, D. J. (2012). The effects of portfolio assessment: Focused on High School Mathematics. Unpublished Master's Thesis, University of Pangasinan

Valdez, D. J., Corpus, B.K. \& Ferrer, H.Y. (2012). The underlying problems in Motivation and Instruction. University Journal

Wiggins, K. A. (2013). Application example of fitness portfolio to improve the health-related fitness. Unpublished Master's Thesis, Inchon National University of Education, Korea.

Wise, L. L. (2015, February). Picking up the pieces: Aggregating results from through-course assessments. Paper presented at the Invitational Research Symposium on Through-Course Summative Assessment. Atlanta, GA. 